\title{
ERRATUM
}

D. B. Kaber • N. Segall • R. S. Green

K. Entzian · S. Junginger

\section{Using multiple cognitive task analysis methods for supervisory control interface design in high-throughput biological screening processes}

\section{Cogn Tech Work (2006) DOl: 10.1007/s10111-006-0029-9}

In the original publication, two additional references should have appeared in the reference list and their associated citations included in the text.

In Sect. 1.2, 4th sentence, a citation of Mazaeva and Bisantz (2003) should appear at the end of the sentence.

In Sect. 3.3, 3rd paragraph, 5th sentence, a citation of Mazaeva and Bisantz (2003) should appear at the end of the sentence.

In Sect. 3.3, 3rd paragraph, 7th sentence, a citation of Mazaeva and Bisantz (in press) should appear at the end of the sentence.

In Sect. 3.3., 3rd paragraph, 9th sentence, a citation of Mazaeva and Bisantz (in press) should appear at the end of the sentence.

The caption for Fig. 2 should read, "Fig. 2 General form of an abstraction hierarchy model (adapted from Mazaeva and Bisantz 2003)".
The caption for Fig. 7 should read, "Fig. 7 AH model for bar coder device (format based on Mazaeva and Bisantz 2003)".

The caption for Fig. 9 should read, "Fig. 9 AH automation model for bar coder action/configuration dialog (format based on Mazaeva and Bisantz 2003)".

The following additional reference information should have been included in the references list:

Mazaeva N, Bisantz A (2003) Modeling automation with an abstraction hierarchy. In: Proceedings of the 47th annual meeting of the Human Factors and Ergonomics Society. Human Factors and Ergonomics Society, Santa Monica

Mazaeva N, Bisantz A (2006) On the representation of automation using a work domain analysis. Theor Issues Ergon Sci (in press)

The online version of the original article can be found at http:// dx.doi.org/10.1007/s10111-006-0029-9

D. B. Kaber $(\bowtie) \cdot$ N. Segall · R. S. Green

Cognitive Ergonomics Laboratory,

Department of Industrial Engineering,

North Carolina State University, Raleigh, NC, USA

E-mail: dbkaber@eos.ncsu.edu

Tel.: + 1-919-5153086

Fax: + 1-919-5155281

K. Entzian

Center for Life Sciences Automation, University of Rostock,

Rostock-Warnemünde, Germany

S. Junginger

Analytical Instrument Group (AIG), e.V.,

Rostock-Warnemünde, Germany 